\title{
LA OBJETIVIDAD DEL AZAR EN LA EVOLUCIÓN DE LAS ESPECIES
}

\section{THE OBJECTIVITY OF CHANCE IN THE EVOLUTION OF SPECIES}

\author{
JOSÉ LUIS ROLLERI" \\ Universidad Autónoma de Querétaro
}

\begin{abstract}
Resumen: En este artículo se analizan diferentes nociones de azar que podrían ser apropiadas para los procesos genéticos de replicación y recombinación así como para los procesos de selección natural. Se mantiene que en evolución hay tres tipos de procesos azarosos objetivos: un azar intrínseco en los procesos de replicación del ADN (que dan lugar a mutaciones espontáneas), un azar puramente combinatorio en los procesos de recombinación y un azar extrínseco a los procesos selectivos estabilizadores, direccionales y disruptivos del fenotipo de los organismos, en virtud de que estos están indisolublemente integrados a un medio ambiente complejo, que está permeado por diversos factores contingentes, aleatorios; factores climáticos, atmosféricos, geológicos e incluso astronómicos. Así, el azar es un factor ubicuo en la evolución de las especies.
\end{abstract}

Palabras clave: proceso estocástico, efecto aleatorio, mutación, replicación, recombinación, proceso selectivo.

Авstract: In this paper, I analyze different notions of chance which could be appropriate to the genetic processes of replication and recombination as well to the processes of natural selection. I maintain that, in evolution, there are three different types of objective chance processes: an intrinsic chance in DNA replication (which gives rise

\footnotetext{
" Dirección postal: 16 de Septiembre 57 Ote., Centro, Querétaro, Qro. C. P. 76000, México. e-mail: jlrolleri@yahoo.com. Profesor investigador de la Facultad de Filosofía.
} 
to spontaneous mutations), a merely combinatory chance in genetic recombination, and a chance that is extrinsic to the stabilizing, directional, and disruptive selection processes of an organism's phenotype, in virtue of which these are indissolubly integrated into a complex environment, which is permeated by a diversity of contingent, random factors: climatic, atmospheric, geological, and even astronomic factors. Thus, chance is a ubiquitous feature in the evolution of species.

KeYwords: stochastic process, random effect, mutation, replication, recombination, selection process.

\section{Introducción}

Desde el surgimiento de la teoría de Darwin, dos han sido los pilares de la teoría de la evolución de las especies: la variación genética y la selección natural. La histórica aportación de Darwin consiste en la fundación de la teoría de la selección natural para explicar ciertos procesos evolutivos claves como la supervivencia de los organismos mejor adaptados y su reproducción diferenciada. Más el otro pilar de la teoría de la evolución, las fuentes de la variación genética, era desconocido para Darwin.

La genética actual se ha desarrollado de tal forma que da respuestas a cuestiones como la siguiente: ¿cómo es posible que haya variación en la dotación de genes característicos de una especie?, en términos de mecanismos como la replicación binaria de células germinales, la recombinación de los cromosomas parentales y la generación de alelos nuevos de los genes que componen el genoma de la especie (véase Griffiths, et al., 1999: 14). Estos procesos se reconocen por la mayoría de los biólogos evolucionistas como procesos estocásticos, al menos en el sentido de que son procesos que tienen efectos impredecibles, como la generación de nuevos genotipos por recombinación y la emergencia de alelos inéditos por replicación.

De hecho, desde Darwin, la variación genética fue considerada un tipo de proceso isotrópico, independiente de la dirección ulterior del cambio evolutivo. Con esto se atribuía a la variación genética un carácter azaroso, puesto que no está determinada para conducirse en cierta dirección; en particular, en la de una mejor adaptación. Sin embargo, la noción de azar explícita de Darwin tiene un carácter puramente epistémico: "He hablado algunas veces como si las 
variaciones $[. .$.$] fueran debidas a la casualidad [chance]. Esto, por supuesto, es$ una expresión completamente incorrecta, pero sirve para confesar francamente nuestra ignorancia de las causas de cada variación particular" (1859: 125). Así, como Laplace (1814), Darwin concibe al azar sólo como una manifestación de nuestro desconocimiento parcial de las causas verdaderas.

De esta manera, en la época de Darwin, había una tensión en la concepción del papel del azar en la evolución de las especies: primero, en sentido óntico, como falta de direccionalidad en la variación genética y, segundo, en sentido epistémico, como expresión de nuestra ignorancia de la vera causa. Esta noción de azar epistémico coexistió con cierta concepción mecanicista de la selección natural en la teoría de Darwin (similar a la manera en que se dio en la concepción del universo físico en Laplace).

Actualmente se percibe cierta indeterminación en los trabajos de los biólogos evolucionistas sobre el papel que juega el azar en el cambio evolutivo. Si bien hay consenso sobre el carácter aleatorio de los procesos genéticos recién mencionados, respecto de selección natural la situación no es clara. Se encuentran vestigios recientes de cierta concepción determinista: "Desde el punto de vista evolucionista, se espera que las poblaciones de organismos diverjan genéticamente en el tiempo por los procesos estocásticos (aleatorios) de la mutación y la deriva genética. La dirección particular de sus cambios evolutivos depende también de procesos determinísticos, particularmente de la selección natural y el flujo genético" (Avers, 1989: 294).

A la vez, en las obras de los biólogos evolucionistas no hay una concepción clara del carácter objetivo de los procesos estocásticos que generan variación genética, ni una noción precisa del tipo de azar que interviene en ellos y en los procesos de selección natural.

El propósito de este ensayo es explorar, a muy grandes rasgos, las nociones de replicación y recombinación genéticas, así como la concepción de la selección natural, para elucidar los tipos de azar que tienen lugar en la evolución de las especies y su carácter objetivo.

De alguna manera me opondré a las siguientes tesis de Mayr, que soslayan el papel de las mutaciones en la producción de genotipos inéditos y la intervención del azar en la selección natural, incluida la supervivencia: 
El material con el que trabaja la selección no es la mutación, sino más bien la recombinación de los genes parentales, que produce nuevos genotipos. Debe recordarse siempre que la selección es un proceso de dos pasos. El primer paso consiste en la producción (mediante la recombinación genética) de una inmensa cantidad de nueva variación genética, mientras que el segundo paso es la retención (supervivencia) no al azar de unas pocas de esas nuevas variantes genéticas (Mayr, 1991: 100).

Sostendré aquí que en la evolución tienen lugar procesos azarosos, de carácter objetivo, de tres tipos: un azar intrínseco en la replicación del ADN, un azar puramente combinatorio en la recombinación genética y, por último, respecto de la selección natural, un azar extrínseco a los procesos de selección estabilizadora, direccional y disruptiva de los fenotipos de los organismos, en virtud de que éstos están indisolublemente integrados a un complejo medio ambiente, permeado de factores contingentes, azarosos. El sentido en que mantengo aquí que el azar en los procesos de replicación, recombinación y selección natural es objetivo es en sentido óntico, en contraste con el epistémico, como se verá posteriormente.

El carácter objetivo del azar en la recombinación es generalmente reconocido por los biólogos evolucionistas. La objetividad del azar que es intrínseco a la replicación genética, en cambio, es más controvertido, aunque menor por parte de los genetistas. La cuestión de si la selección natural, que opera a nivel organísmico y de especie - es decir, a nivel microevolutivo- es objetivamente de carácter determinista o estocástico es, hasta donde veo, todavía una cuestión en debate. No pretendo, desde luego, probar que los procesos de selección natural sean procesos estocásticos (los cuales dan lugar a distintos efectos alternativos bajo las mismas condiciones causales) en lugar de procesos deterministas (en los cuales ciertas condiciones causales producen en todos los casos los mismos efectos); si esto fuese posible sería labor propia de los biólogos evolucionistas. En todo caso, asumiré la primera opción con base en las hipótesis al respecto de varios prominentes teóricos de la evolución.

En la exposición y discusión sobre el azar en este ensayo me ajustaré, en buena medida, a los términos que los biólogos evolucionistas utilizan, en los diversos contextos, particularmente con respecto a 'mecanismo', 'azar', 'aleatorio' y 'contingente'. Intentando mayor precisión, sin embargo, hablaré de procesos estocásticos - en oposición a procesos deterministas- que producen efectos 
aleatorios. ${ }^{1}$ Para ello, puedo parafrasear, adecuándolas al presente contexto, las nociones de sistema determinista y sistema estocástico debidas a Giere (1976: 327). Sea $X$ un sistema biológico, una población de organismos, un organismo o un gen en el que se dan procesos de cierto tipo con alguna regularidad. Diré que un proceso en $X$ es determinista si es posible que $X$ transite o se transforme a exactamente un estado final, dado cierto estado inicial de éste. En cambio, un proceso en $X$ es estocástico si, dado cierto estado inicial, es posible que $X$ transite o se transforme, alternativamente, a dos o más estados finales. Si concebimos un mecanismo como el modo en que se generan regularmente procesos de cierto tipo, denominaré sólo de manera derivativa, en el segundo caso, 'estocástico' al mecanismo mismo mientras que a los posibles estados finales alternativos los llamaré 'efectos aleatorios'. Debo anotar que en este sentido los "mecanismos", sean deterministas o estocásticos, tienen un carácter abstracto -i.e., son conceptos que abstraemos de lo que acontece con regularidad en el mundo natural- a diferencia de los procesos mismos, que son las entidades concretas de las que predicamos que son deterministas o estocásticas.

\section{La objetividad del azar en la variación genética}

Intentaré defender que hay dos tipos de azar que intervienen en la generación de variación genética, esclareciendo su carácter objetivo. Primero, en la replicación binaria del ADN de las células germinales tiene lugar un azar intrínseco, isotrópico, que ocasionalmente produce alternativos alelos inéditos, que son la fuente primaria de la innovación evolutiva. Segundo, en la recombinación genética, en especies de reproducción sexual, se da una combinatoria aleatoria de las dotaciones genéticas parentales que produce genotipos nuevos. El resultado de ambos tipos de procesos son genotipos nuevos pero con una diferencia crucial desde un punto de vista evolutivo. La recombinación genera genotipos nuevos, pero la novedad de éstos está acotada a las combinaciones posibles de los genes parentales. En cambio, en la replicación genética se generan ocasionalmente genotipos inéditos, por la incorporación de alelos mutantes alternativos. Hay, desde luego, un vínculo importante de complementación entre estos dos tipos

\footnotetext{
${ }^{1}$ En la teoría de las probabilidades, las expresiones 'proceso estocástico' y 'proceso aleatorio' se utilizan como sinónimos, aunque la primera se elige cuando se introduce un parámetro temporal, véase Feller (1950): 417, n. 28). Como aquí asumiré tácitamente un parámetro tal usaré esa primera expresión.
} 
de procesos genéticos, porque cuando alguno de los progenitores produce un alelo mutante se integrará en la formación de un gameto y, de ahí, es probable que en el proceso ulterior de recombinación se incorpore al cigoto producido, que ostentará entonces una innovación que podría resultar beneficiosa para la supervivencia del individuo que genere.

De acuerdo con los genetistas, existen dos modos en que se generan regularmente procesos de variación hereditaria. Por la replicación genética, el primero, nuevos alelos aparecen de manera espontánea en los organismos, produciendo eventualmente alelos mutantes. Las mutaciones, sean puntuales o cromosómicas, son la fuente primaria del cambio genético. Durante la replicación del ADN, las dos hebras de la doble hélice se separan y cada cadena sencilla sirve de molde para la polimerización de los nucleótidos. Este tipo de replicación es semiconservativa en el sentido de que cada molécula hija de $\mathrm{ADN}$ es mitad vieja y mitad nueva. La replicación del $\mathrm{ADN}$ en las células eucariotas precede a la meiosis, a la división nuclear que produce núcleos hermanos.

El tipo de mutaciones que alteran una sola base de $\mathrm{ADN}$, o un número reducido de bases adyacentes, acontece con baja frecuencia, en el rango de una célula de cada $10^{5}$ a $10^{8}$, sin embargo, aunque muy escasas tienen la capacidad de producir espontáneamente la modificación de un gen a otra forma génica de manera natural, no inducida (véase Griffiths, et al., 1999: 121, 130 y 198).

Las mutaciones que aquí nos conciernen son las que aparecen en la línea germinal, mutaciones germinales, que es un tejido muy especial que en el desarrollo se diferencia para formar gametos. Cuando un gameto portador de una mutación participa en la fertilización, la mutación será transmitida a la siguiente generación. Dentro de la diversidad de mutaciones que se dan en los organismos multicelulares - dejando a un lado las mutaciones en células somáticas-, las hay, muy infrecuentes, que incrementan la actividad de un gen o alteran el lugar donde se expresa, denominadas mutaciones de ganancia de función (Griffiths, et al., 1999: 222 y 198). La tasa de generación de mutaciones espontáneas varía en un amplio rango. Por su parte, las mutaciones de células germinales varían, en función de sus interacciones con otros genes y con el medio ambiente, en su penetración que es la proporción de los organismos en los que se expresa una mutación y en su expresividad que es la severidad del fenotipo que se atribuye a un alelo (Griffiths, et al., 1999: 183). 
Sea como sea, aunque escasas, hay mutaciones en las células germinales que producen genotipos nuevos en organismos individuales, los cuales pueden tener efectos en su fenotipo, modificando una estructura o una función. Estas mutaciones son efectos aleatorios de ciertos procesos estocásticos (no deterministas) de replicación y son evolutivamente significativas.

El otro modo de generación de variación genética es la recombinación. Los nuevos alelos producidos por replicación se convierten en la materia prima de un segundo nivel de variación. Precedida por la replicación, la recombinación es un tipo de proceso en el que se combinan (se "barajan") los genes que forman pares alélicos heterocigotos u homocigotos y se reparten dando lugar a distintas combinaciones en los productos de la meiosis (óvulos y espermatozoides) en plantas y animales (Griffiths, et al., 1999: 130). Los procesos genéticos de recombinación producen genotipos nuevos dentro de la enorme gama de posibles combinaciones de los genes aportados por los progenitores. La siguiente cita da una idea de las posibles variaciones generadas por recombinación: "Si suponemos, por ejemplo, que un organismo diploide es heterocigoto para 10 genes (estimación muy a la baja para la mayoría de los organismos), el número total de genotipos posibles de los gametos sería: $2^{10}=1024 "$ (Griffiths, et al., 1999: 130).

Debemos percatarnos, sin embargo, de que este modo de generación de variación genética sólo recombina los genes disponibles de las dotaciones parentales. Aunque produce nuevos genotipos, todos ellos, a nivel de especie, son variaciones de un mismo tema: el genoma de la especie. Si bien es cierto que el número de recombinaciones posibles es inmenso e inagotable a nivel de especie - como en el caso de la especie Homo sapiens, cuyo genoma contiene 3,000 millones de caracteres A, T, C y G (símbolos para adenina, timina, citosina y guanina), que corresponden a los nucleótidos del ADN, en los que la variación entre dos individuos es del orden de un carácter por cada mil—, si no hubiera modo alguno en que se modifique el pool o acervo genético de una población de cierta especie, produciendo ocasionalmente genotipos inéditos, entonces no habría innovación evolutiva significativa. Ese tipo de modificaciones del acervo genético de poblaciones y especies, a nivel microevolutivo, las aportan las mutaciones heredables, que tienen efectos en el fenotipo de los organismos individuales. ${ }^{2}$

\footnotetext{
${ }^{2}$ Los biólogos evolucionistas reconocen otro factor de cambio genético que llaman 'deriva genética', la cual consiste en fluctuaciones impredecibles en las frecuencias alélicas de una población. Cuando la población es pequeña en número y está separada espacialmente de otras se aísla reproductivamente, lo que da lugar a que el flujo genético del acervo de la especie se
} 
¿Cómo surgen las variantes genéticas? Lewontin y sus colegas dicen que la respuesta es sencilla: "[...] los organismos tienen una tendencia inherente a sufrir cambios desde un estadio hereditario a otro. Este cambio hereditario se denomina mutación." (Griffiths, et al., 1999: 198). Esta concepción de las mutaciones atribuye un carácter objetivo a los procesos estocásticos que las producen, en tanto que las considera el resultado de tendencias inherentes a los organismos.

Aunque se encuentra un consenso entre los biólogos evolucionistas acerca de la aleatoriedad de las mutaciones, no existe un acuerdo sobre el carácter objetivo del azar en los procesos que generan los alelos mutantes. Hay, al menos, dos concepciones acerca de esto. Una considera que las mutaciones son el resultado de fallas a la fidelidad de la replicación: "Las mutaciones son aleatorias porque son raras excepciones a la fidelidad del proceso de replicación del ADN, que surgen como resultado de causas físicas que no son deterministas (o al menos que no pueden determinarse por el conocimiento científico actual)." (Ayala, 2012: 51). La otra considera las mutaciones como errores en los procesos de replicación de ADN: "Las mutaciones espontáneas, por definición, no tienen causas conocidas, pero errores de copiado [copying errors] durante la replicación del ADN pueden ser responsables de una gran fracción de variación alélica” (Avers, 1989: 162). Incluso Lewontin y sus colegas parecen compartir esta última concepción de las mutaciones cuando escriben que "Las mutaciones espontáneas se originan por errores de replicación o por lesiones espontáneas, tales como las generadas por desaminación o despurinización. Estas dos fuentes generan la mayor parte de las mutaciones génicas" (Griffiths et al., 1999: 226).

Estas dos concepciones guardan en común que consideran la replicación genética un mecanismo que tiene que producir copias exactas, idénticas, de cada gen o unidad de ADN cromosómico, y nada más. Ayala se pronuncia explícitamente sobre esta última cuestión: "Por regla general, la información codificada en la secuencia de nucleótidos se reproduce fielmente durante la replicación [...] La fidelidad del proceso es enorme, pero no es perfecta. Ocasionalmente, en la molécula de ADN tienen lugar mutaciones durante la replicación” (2012: 65). Esta

reduzca significativamente a los organismos individuales que forman la población en cuestión. Esto puede conducir a un tipo de especiación que Mayr llama alopátrica, si es que ulteriormente interviene algún mecanismo de aislamiento reproductivo, sea precigótico o postcigótico. La deriva genética es un fenómeno estadístico al que subyacen mecanismos de variación genética a nivel molecular que son los responsables, en última instancia, de la especiación alopátrica, puesto que en una población pequeńa, la penetración y expresividad de las mutaciones pueden tener efectos considerables. 
concepción de las mutaciones se antoja un tanto paradójica puesto que el propio Ayala atribuye un papel protagónico a las mutaciones - que resultan favorables en cierto medio ambiente para los organismos que las portan y son seleccionadas y transmitidas de manera natural - en la evolución de las especies: "Mutación y selección han impulsado conjuntamente el maravilloso proceso que, empezando desde organismos microscópicos, ha producido orquídeas, pájaros y humanos." (2012: 51). No deja de ser paradójico que un tipo de proceso que ha generado innovación evolutiva, y que es la fuente primaria del cambio genético, se deba a una imperfección, a una falta de fidelidad de un mecanismo natural. Considero que esta incongruencia responde a una resistencia de reconocer el carácter objetivo, intrínseco, del azar en las mutaciones de las moléculas del ADN.

La otra interpretación del azar en las mutaciones, que las atribuye a errores en el proceso de replicación, presupone que el mecanismo de replicación celular es imperfecto ya que ocasionalmente comete errores. Las mutaciones genéticas son el resultado de esos errores que ocurren aleatoriamente ${ }^{3}$.

En el contexto de una discusión con Popper, Kuhn afirma: "Un error es algo que se hace, o se comete, en un tiempo y un lugar determinados por un individuo particular. Ese individuo ha dejado de obedecer alguna regla establecida de la lógica, o del lenguaje, o de las relaciones entre uno de éstos y la experiencia." (1970: 92). Si asumimos esta idea básica, en una primera instancia un error sería un acto humano que consiste en no seguir una regla dentro de un ámbito de acción determinado. Extrapolada esta idea de error a un mecanismo natural significaría que hay reglas que el mecanismo no sigue al producir un proceso determinado. Aquí el individuo que comete el error es el mecanismo de replicación genética de un organismo individual mientras que el error consiste en el alelo mutante producido. Pero ¿̇cuáles son las reglas que nos permiten sancionar las mutaciones como errores? Pienso que las mutaciones se consideran errores sólo precisamente porque son mutaciones, es decir, porque son resultados aleatorios

\footnotetext{
${ }^{3}$ Desde la genética de poblaciones, que adopta un enfoque metodológico estadístico, se ha asociado a la deriva genética la idea de errores de muestreo como un factor que produce nuevos genotipos. Si una población pequeña se aísla geográficamente, el flujo genético del acervo de la especie se reduce drásticamente. Si se toma la población, o parte de ella, como una muestra entonces a la aparición y eventual fijación de algún nuevo rasgo en el fenotipo en dicha muestra se considera un error. Así, la aparición de un alelo mutante, alternativo al alelo silvestre, en algunos organismos de la muestra sería un error de muestreo. Este enfoque estadístico soslaya el cambio a nivel molecular del ADN que da lugar al alelo mutante.
} 
de procesos estocásticos, de procesos espontáneos que no siguen la regla de la replicación fidedigna, perfecta.

No es mi intención defender la tesis de que la naturaleza es en sí misma imperfecta, ya que no tengo la menor idea de lo que esto podría significar. Pero los biólogos que conciben las mutaciones espontáneas y aleatorias como errores del mecanismo de replicación genética parecen suponer tácitamente alguna noción de perfección en la naturaleza ya que de acuerdo con ellos, las mutaciones se deben a errores en ese mecanismo natural. Esto significaría que la fuente primaria del cambio evolutivo, los genotipos inéditos, es un resultado de errores de un mecanismo natural, e implicaría que si ese mecanismo no cometiera errores entonces no habría cambio evolutivo significativo. La perfección de la replicación genética suprimiría la materia prima de ciertos procesos evolutivos innovadores.

Hay, no obstante, una interpretación filosófica alternativa de las mutaciones como efectos de procesos estocásticos que no involucra ese tipo de consecuencias inconsistentes. Considero que esas concepciones recién criticadas son un resabio del determinismo laplaceano aunado a la concepción epistémica del azar como expresión de nuestro desconocimiento de las verdaderas causas, concepciones que Darwin adoptó.

En la física atómica, durante los años treinta, Einstein y Bohr protagonizaron una discusión sobre el indeterminismo cuántico que desembocó en la cuestión de resolver si el azar observado en ciertos procesos atómicos — como la desintegración, la fusión y la fisión- es objetivo, intrínseco a los sistemas cuánticos, o es epistémico, debido a nuestro desconocimiento de magnitudes — denominadas 'variables ocultas' - que determinarían causalmente ese tipo de procesos que son sólo aparentemente aleatorios. ${ }^{4}$ Sin pretender que ese debate sobre el carácter objetivo del azar cuántico esté agotado, pienso que la balanza se ha inclinado en favor de la tesis de la objetividad del azar en los procesos cuánticos porque los experimentos llevados a cabo desde 1982 por Aspect y sus colaboradores han constatado la irreductibilidad de los enunciados de probabilidades de la teoría cuántica considerados como la expresión cuantitativa o medida del azar cuántico (véase, p. ej., Rae, 1986; Cushing, 1989). Esto significa que el azar observado

\footnotetext{
${ }^{4}$ Es digno de notar en este contexto que a diferencia de los procesos de fusión y fisión, en los que interactúan al menos un par de partículas, los procesos de desintegración radioactiva y de cambio discontinuo de nivel de energía (los llamados 'saltos cuánticos') acontecen espontáneamente.
} 
en los procesos cuánticos es objetivo, es un tipo de azar que es intrínseco a los sistemas cuánticos, independiente de nuestras limitaciones de conocer el mundo a nivel atómico. Martínez ha elaborado un concepto de azar sistémico, que atribuye acertadamente a los sistemas cuánticos:

Un azar objetivo no epistémico tiene que expresarse como la descripción de un aspecto de la estructura del mundo, incorporado en la descripción de estado según una teoría fundamental de la física (independientemente de las limitaciones de nuestra manera de observarlo o conocerlo que puedan existir). A este tipo de azar objetivo le llamaremos azar sistémico. Es un tipo de azar objetivo que es intrínseco a la descripción de estado que la teoría utiliza (1991: 139-140).

Por supuesto, esta concepción filosófica del carácter objetivo de la aleatoriedad en el campo de la física atómica echa por la borda en un solo manojo a la concepción determinista del universo físico y a la concepción epistémica del azar como ignorancia de las verdaderas causas de Laplace.

Paralelamente, se puede concebir que los procesos genéticos que generan la variación -en particular, la emergencia de genotipos inéditos por la incorporación de mutaciones - son procesos objetivamente estocásticos. Las interpretaciones del modo de generación de las mutaciones espontáneas de los biólogos evolucionistas que aquí rechazo trasladadas al campo de la física atómica adoptarían la forma de un mecanicismo imperfecto en el universo físico, como un reloj mecánico que ocasionalmente se retrasa o se adelanta de manera impredecible. En la actualidad, este orden de ideas sería totalmente implausible en el campo de la física atómica, sin embargo parece campear en la biología evolutiva; quizá debido a una reticencia a reconocer que las mutaciones genéticas son intrínseca y objetivamente aleatorias, en sentido óntico.

En suma: los procesos de replicación genética son intrínsecamente azarosos; son procesos isotrópicos que ocasionalmente producen genotipos inéditos. El surgimiento de mutaciones germinales - sea que a la postre resulten beneficiosas, neutrales o deletéreas- es el resultado esporádico de procesos que son objetivamente estocásticos: la replicación del ADN.

El otro modo de generación de variación genética es la recombinación. Los biólogos evolucionistas conciben que este modo de combinación de alelos y pares 
de bases cromosómicas aportadas por los progenitores es aleatorio. He sugerido que la aleatoriedad propia de la recombinación genética es objetiva, inherente al procedimiento de combinación al azar de las contribuciones genéticas de los progenitores. No tengo más que agregar ahora, salvo insistir en que la variación que se genera por recombinación está acotada a las posibles combinaciones de las aportaciones genéticas de cada uno de los progenitores y que si bien genera nuevos genotipos, éstos no son más que variaciones de un mismo tema: el genoma de la especie.

Recapitulando: hay dos tipos de procesos que producen variación genética. En una primera instancia, el de la mutación, que es la fuente primaria del surgimiento de genotipos inéditos; en una segunda instancia, el de la recombinación, que genera la materia prima de la selección natural. Los nuevos genotipos arrojados por recombinación genética integran las mutaciones que previamente hubieran tenido lugar en las células germinales. Conjuntamente, ambos tipos de procesos genéticos son, en parte, responsables de la innovación evolutiva.

Un principio de la biología evolutiva es que el genotipo determina el fenotipo de los organismos. Y como anota Kardong, es el fenotipo el que llega cara a cara con la selección natural $(2005,106)$. De tal manera, lo que se selecciona son los fenotipos de los organismos en poblaciones de cierta especie ${ }^{5}$.

\section{La objetividad del azar en la selección natural}

La selección natural, vista como un megaproceso histórico, dista mucho de ser un proceso determinístico, exento de azar, porque en ella han intervenido, e intervienen, procesos contingentes, desde cambios atmosféricos, geológicos,

\footnotetext{
${ }^{5}$ Definir el concepto de especie es una labor sumamente compleja; véase Ereshefsky (2010). Existen varias propuestas de definición pero no hay consenso sobre alguna de ellas. El concepto que goza de mayor aceptación es el llamado concepto biológico debido a Mayr, definido como: "las especies son grupos naturales con cruzamiento entre sí que están reproductivamente aislados de otros grupos." (Mayr (1991): 42). Este concepto está expuesto a la obvia restricción a especies de reproducción sexual. En el contexto de este ensayo prefiero, por su generalidad y neutralidad, la definición de especie como una colección de poblaciones que comparten un acervo o pool de genes (cfr. Avers (1989): 232). Como la información genética que contienen las moléculas de $\mathrm{ADN}$ vale tanto en animales, plantas, bacterias como en hongos (con la excepción de los virus) ese concepto genético de especie tiene una amplia aplicación.
} 
climáticos, hasta sucesos fortuitos astronómicos como el impacto de meteoritos. La consecuencia de esto es que en los complejos procesos de supervivencia y éxito reproductivo de organismos, poblaciones y especies, confluyen procesos azarosos que son extrínsecos a las poblaciones que en fusión con los recursos bióticos y abióticos conforman un ecosistema. Concebir la selección natural como un proceso exento de cualquier factor azaroso es una idealización que aunque podría ser legítima y permisible para ciertos propósitos es una simplificación en demasía irrealista e incluso contrafáctica.

Generalmente se considera la selección natural es el mecanismo de la evolución (véase, p. ej., Eldredge, 1999: 119). Una exposición sucinta de la concepción de la selección natural, consistente con la de Darwin, es la siguiente:

Una formulación básica —el esqueleto- de la selección natural es un argumento basado en tres hechos innegables (sobreproducción de descendencia, variación y heredabilidad) y una inferencia silogística: la selección natural, o la afirmación de que los organismos con más éxito reproductivo serán, en promedio, las variantes que, por azar, resulten mejor adaptadas a los entornos locales cambiantes, las cuales, por herencia, transferirán a sus descendientes sus rasgos favorecidos. (Gould, 2002: 37).

Podemos hacer hincapié en que el nivel de actuación de la selección (como lo sugiere la anterior cita) es el del organismo. Son, en una primera instancia, los organismos individuales los que son seleccionados. Sin embargo, la selección a ese nivel tiene consecuencias selectivas más allá del individuo, como lo explica Mayr:

La selección al nivel de organismo en su conjunto tiene como resultado cambios en otros dos niveles: el del gen, donde a través de la selección de individuos ciertos genes pueden aumentar o disminuir su frecuencia en la población, y en la especie, donde la superioridad selectiva de los miembros de una especie puede conducir a la extinción de otra especie. (1991: 101).

Actuando sobre los diversos fenotipos que portan los organismos individuales producidos por la variación genética, la selección natural conduce el cambio evolutivo, por procesos estabilizadores, direccionales y disruptivos. Estos procesos naturales seleccionan rasgos o caracteres en función de que resulten benéficos o perjudiciales en determinado medio ambiente. En primer lugar, la selección estabilizadora, la más frecuente, elimina los fenotipos extremos cuando resultan 
desventajosos y favorece los fenotipos intermedios. La selección direccional, por su parte, elimina un fenotipo extremo si resulta perjudicial o nocivo, desapareciéndolo a la larga. Por último, cuando un fenotipo intermedio es deletéreo, la selección disruptiva actúa contra éste eliminándolo, a la vez que favorece a los fenotipos extremos y divide en dos a la población, dando lugar al fenómeno del polimorfismo, i. e., dos formas distintas de una misma especie (cfr. Kardong, 2005: 114-115).

De tal suerte, sea por uno u otro de los anteriores procesos, algunos fenotipos son preservados y otros son eliminados. Este mecanismo de selección ocasiona que ciertas poblaciones optimicen su aptitud (fitness) - capacidad de supervivencia y transmisión de genes- y alcancen el pico de una cima adaptativa (adaptedness) -adecuación al medio ambiente y forma de vida.

Algunos biólogos evolucionistas sugieren que el mecanismo de selección natural, que da lugar a poblaciones de organismos adaptados, eficaces para supervivir y reproducirse, es un mecanismo causal. Por ejemplo, Gould escribe que: "[...] la selección natural construye la adaptación; la selección natural mantiene una abrumadora predominante frecuencia relativa como causa de la adaptación. La variación sólo proporciona materia prima y no puede hacer el trabajo sin ayuda." (2002: 184). Por su parte, Kardong dice que: "La selección natural es la causa de la divergencia y diferenciación, pero no puede ser la causa directa de los mecanismos de aislamiento reproductivo [...]. Pero una vez que la selección natural ha causado caracteres supervivientes en esas poblaciones como para divergir significativamente, el aislamiento reproductivo es un efecto lateral." (2005: 144). De manera indirecta: "La transmisión de las variaciones hereditarias de una generación a la siguiente está regida en gran parte por el proceso no aleatorio de la selección natural, aunque también hay un componente aleatorio que los genetistas llaman 'deriva genética'.' (Ayala, 2012: 49).

Estos autores no elucidan el significado de la noción de causa que atribuyen a procesos naturales de selección de organismos y poblaciones, pero en todo caso, desde la época de Darwin, los evolucionistas rechazan las causas finales, en el sentido de que la selección se conduzca para cumplir con algún diseño preestablecido (véase Mayr 1991: cap. 5). Más bien ellos consideran que los factores causales en ciertos procesos de selección son causas en el sentido de causa eficiente, aunque no las conciben, á la Laplace, como causas suficientes, deterministas, sino como condiciones naturales que producen ciertos efectos (antes que nada, la supervivencia) sólo de manera probabilista. Esto se refleja en 
ciertas formulaciones del principio de selección natural en términos causales y probabilistas, como la propuesta por Brandon:

Típicamente (pero no necesariamente) hay variación entre los organismos dentro de una población reproductiva. Con frecuencia (pero no siempre) esta variación es (en algún grado) heredable. Cuando está variación está causalmente conectada a una habilidad diferencial de supervivir y reproducir, probablemente sucederá una reproducción diferencial. (2008: 2).

Con todo, lo que queda claro es que los procesos naturales de selección - como los procesos de selección estabilizadora, direccional y disruptiva- no son procesos deterministas, procesos que produzcan siempre los mismos efectos para todos los organismos con toda probabilidad (la noción de causa probabilista que elabora Suppes (1970) — que consiste básicamente en que las condiciones causales aumentan la probabilidad del efecto o, alternativamente, que si ciertas condiciones específicas aumentan la probabilidad de que acontezca un suceso entonces éste es considerado como un efecto de aquéllas- resulta apropiada para expresar el tipo de causalidad que tiene lugar en tales procesos naturales).

Hay una aparente tensión entre la concepción causal de la selección natural y el azar que permea ciertos procesos selectivos. Por ejemplo, ¿qué quiere decir Gould cuando se refiere a "las variantes que, por $a z a r$, resulten mejor adaptadas", a la vez que considera que la selección natural construye la adaptación, que es la causa principal de la adaptación? Podemos disolver esta tensión reconociendo que en evolución los factores causales son sólo probabilistas mientras que el azar es objetivo, óntico. Concebir la causalidad en la selección natural con un carácter probabilista a la vez que se considera objetivamente el azar que interviene en ciertos procesos selectivos -alternativa que se ha abierto tácitamente en las últimas décadas en el campo de la biología evolutiva-, aleja considerablemente la teoría actual de la evolución de la concepción laplaceana, que adoptó Darwin, de un mundo causado de modo determinista así como de un azar epistémico, como ignorancia de las causas verdaderas. Un movimiento similar de alejamiento de la concepción laplaceana en el campo de la física, tuvo lugar en la mecánica cuántica cuando se demostró que los enunciados cuánticos probabilistas son irreductibles a enunciados deterministas que apelaran a causas subyacentes -las llamadas 'variables ocultas'- y, con ello, que el azar o indeterminismo cuántico tiene un carácter objetivo, óntico ${ }^{6}$.

${ }^{6}$ Véanse Rae (1986), Suppes (1984) y Martínez (1991). 
Lo anterior nos acerca al tema de este ensayo: la objetividad del azar en la teoría de la evolución. ¿Cómo interviene el azar en la selección natural? Desafortunadamente, no hay un concepto de azar o de efecto aleatorio o de proceso estocástico, o algo así, respecto de la selección natural que impere en la biología evolutiva. Pareciera que la aceptación de factores y procesos azarosos se restringe a los procesos genéticos - mutación, recombinación, deriva-, excluyendo al azar del ámbito de los procesos de selección -estabilizadora, direccional y disruptivacomo si fuesen procesos deterministas.

Esto puede constatarse en la posición a este respecto de Sober, quien rechaza que la selección natural sea un proceso aleatorio sin afirmar que sea un proceso determinista. En una discusión crítica con los creacionistas actuales - quienes arguyen que si la selección natural es aleatoria no puede crear orden del desorden-, Sober limita la aleatoriedad a los procesos de deriva genética cuando los alelos en cierto locus en una población tienen igual (o casi igual) aptitud (fitness) (cfr. Sober, 2000: 37). A partir de expresar la noción de aptitud en términos de probabilidades de sobrevivencia y reproducción, él contempla la posibilidad de que el azar (chance) desempeñara un papel en la evolución por selección natural, para rehusarla argumentando que: "La selección natural involucra probabilidades desiguales, y por esta razón, no es un proceso aleatorio. [...] La aleatoriedad es una cuestión importante en la teoría de la evolución, pero no es parte del proceso de selección natural." (2000: 37). La razón que ofrece Sober es simplemente que: "Si un proceso es aleatorio, entonces diferentes posibilidades tienen la misma (o casi la misma) probabilidad. [...] Sin embargo, cuando las diferentes posibilidades tienen probabilidades drásticamente desiguales, el proceso no es aleatorio.” (2000: 37).

Trasladado este orden de ideas a los procesos cuánticos, se obtiene que el proceso de fusión de dos deuterones ${ }^{2} d+{ }_{1}^{2} d$ sería un proceso aleatorio porque las dos rutas alternativas de transformación - que se forme un núcleo de ${ }_{2}^{3} \mathrm{He}$ más un neutrón o un núcleo de tritio-3 más un protón- son igualmente probables, mientras que la desintegración del elemento radioactivo bismuto-212 no sería un proceso aleatorio ya que las dos rutas alternativas de conversión tienen probabilidades desiguales -el decaimiento negativo $\beta$ que origina polonio, ${ }^{212}$ Po, tiene una probabilidad igual a 0.663 y el decaimiento $\alpha$ que origina talio, ${ }_{81}^{208} \mathrm{TI}$, tiene una probabilidad igual a 0.337 . Hacer en la teoría cuántica esta distinción entre procesos aleatorios y procesos no aleatorios -con base en el criterio de que los primeros tienen probabilidades (casi) iguales mientras que las probabilidades de los segundos son desiguales- es totalmente arbitrario; no 
lo es menos en la teoría de selección natural. El sello de aleatoriedad de un proceso radica en que acontezcan alternativamente distintos efectos posibles (no un solo efecto necesario), dado cierto tipo de condiciones objetivas iniciales, y no en la alguna relación -igual o desigual- entre las probabilidades de los efectos posibles, como pretende Sober.

Con todo, el propio Darwin explica la supervivencia de los organismos, idea clave en la teoría de selección natural, como un proceso probable:

Como en cada especie nacen muchos más individuos de los que pueden sobrevivir, y como, en consecuencia, hay una lucha por la vida, que se repite frecuentemente, se sigue que todo ser, si varía, por poco que sea, de algún modo provechoso para él bajo las complejas y a veces variables condiciones de vida, tendrá mayor probabilidad de sobrevivir y de ser seleccionado naturalmente. (1859: 9).

O como lo dice concisamente Eldredge: "Sobrevivir es tanto una cuestión de suerte como cualquier otra cosa. Y la evolución reconstruye con base en lo que sobrevive." (1999: 153).

En la interpretación de la teoría de Darwin, Gould atribuye al cambio evolutivo un carácter contingente, en oposición a cierta concepción determinista predarwiniana:

La teoría de Darwin, en marcado y revolucionario contraste, presenta la primera interpretación "externalista" de la evolución en la que el cambio contingente (la suma de adaptaciones locales impredecibles en vez del despliegue determinista de un potencial inherente conforme a principios biológicos internos) procede mediante la interacción entre la materia prima orgánica (variación no dirigida) y la conducción medioambiental (selección natural) (2002: 187).

La confluencia de procesos contingentes en procesos asociados a la selección natural la convierten en un mecanismo no determinista, un mecanismo estocástico que da lugar a una variedad de procesos en los que hay algún factor contingente que produce algún efecto azaroso.

Como he anotado, la selección natural como un megaproceso histórico está permeada por procesos contingentes como son cambios atmosféricos, geológicos, 
climáticos y astronómicos. Estos procesos son externos e independientes a los procesos naturales de selección pero han desempeńado y desempeñan, de manera intermitente, un papel significativo en los complejos procesos de supervivencia y éxito reproductivo de organismos, poblaciones y especies, así como en su extinción, a nivel macroevolutivo.

No obstante, los anteriores procesos contingentes no son biológicos. Para intentar elucidar cómo el azar interviene propiamente en la selección natural debemos concentrarnos en los procesos de preservación y eliminación de fenotipos: los procesos de selección estabilizadora, direccional y disruptiva. En primera instancia, hay factores azarosos en la supervivencia y reproducción exitosa que provienen de la presión selectiva que ejercen factores ambientales, en constante cambio, en los fenotipos de organismos. Como señalan Lewontin y sus colegas, puesto que los caracteres de los individuos varían en forma, tamaño, color, etcétera, la presión selectiva actuando sobre una población — conjuntamente con la selección sexual- retiene a algunos individuos y elimina a otros (cfr. Griffiths, et al., 1999: 113ss). Entonces, en una primera instancia el azar en la selección natural provendría de la variabilidad genética combinada con la presión selectiva ejercida por un medio ambiente que cambia contingentemente. La preservación de ciertos organismos y la eliminación de otros, en función de los fenotipos que portan, serían efectos aleatorios de una compleja interacción de las poblaciones, que comparten y conforman un ecosistema, entre ellas mismas y con un medio ambiente local y concreto, debidos a la presión selectiva.

Sin embargo, la situación es algo más complicada. Debemos percatarnos de que los organismos y las poblaciones que se someten a procesos de selección natural viven en, e interactúan con, determinado ecosistema. Como Lewontin señala:

[...] no hay "un medio ambiente" en algún sentido independiente y abstracto. Así como no hay un organismo sin un medio ambiente, no hay un medio ambiente sin organismo. Los organismos no experimentan medios ambientes. Crean esos medios ambientes. Construyen su medio ambiente a partir de partes y piezas del mundo físico y biológico y lo hacen mediante su actividad propia. ${ }^{7}$

7 Richard Lewontin, Biology as Ideology. The Doctrine of DNA, Harper Perennial, 1991:109 (citado por Sergio Martínez, De los efectos a las causas, México, Paidós/UNAM, 1997: 166). 
Gould también enfatiza esta situación cuando explica que por medio ambiente "[...] se entiende, por supuesto, el conjunto de factores bióticos y abióticos externos al organismo, aunque intrínsecamente trabados con él, y hasta definidos en gran medida por su presencia." (2012: 187).

Entonces, no debemos abstraer a las poblaciones, separándolas conceptualmente del ecosistema del que forman parte. Al hacer esto sólo seríamos capaces de ver los procesos azarosos involucrados en función de esa población y de nada más. Si, al contrario, tomamos en cuenta el ecosistema o sistema biológico global, incluidos los elementos físicos, tal vez podríamos elucidar cómo intervienen factores azarosos en procesos de selección natural. Debemos considerar el azar en la selección natural en virtud de los procesos de selección estabilizadora, direccional y disruptiva que producen preservación y eliminación de fenotipos, en lugar de en función de alguna población en particular. Planteada la cuestión de este modo, el azar en la selección natural es extrínseco a los procesos selectivos, puesto que proviene de múltiples y diversos factores azarosos en la compleja selección de fenotipos, en función de las interacciones internas del sistema biológico global y de factores externos, tales como contingencias atmosféricas, climáticas y astronómicas.

\section{Conclusiones}

La evolución de las especies está permeada por procesos estocásticos cuyos efectos son aleatorios. La replicación genera mutaciones de manera espontánea y cada uno de los procesos a que da lugar son estocásticos y los efectos que producen, las mutaciones, son aleatorios. El carácter objetivo de las mutaciones en tanto efectos aleatorios reside en que tienen lugar espontáneamente y son intrínsecas al modo natural que las genera. Las mutaciones como procesos naturales no son inducidas por factores externos al mecanismo genético mismo. La significación de los procesos genéticos que producen mutaciones es cardinal porque son la fuente primaria del cambio genético y, eventualmente, de la innovación evolutiva.

Considero que el pleno y franco reconocimiento del azar objetivo intrínseco que genera alelos mutantes es de la mayor importancia puesto que en este tipo de azar residiría la clave de los procesos macroevolutivos de especiación: la 
generación de nuevas especies; cuestión que es central en la teoría actual de la evolución. $^{8}$

La recombinación genética y los procesos que genera son también estocásticos, y los genotipos nuevos que producen son efectos aleatorios. La objetividad de la recombinación radica en que es una combinatoria de posibilidades de genes, pares de bases y segmentos de $\mathrm{ADN}$ cromosómico de las contribuciones parentales. La enorme importancia de los efectos aleatorios de estos procesos genéticos reside, desde luego, en que son la materia prima de la selección natural.

Estos dos modos de generación de variación genética confluyen en la formación de genotipos inéditos en las filogenias de las especies, puesto que las mutaciones son integradas en los gametos y, de ahí, a los cigotos. Éstos son portadores de los genotipos inéditos. Esto es de máxima importancia porque puede tener repercusiones a nivel macroevolutivo cuando el Bauplan, el plan de construcción, de las estructuras básicas morfológicas de las poblaciones es sustancialmente modificado. Las modificaciones consecuentes de gran magnitud en el fenotipo de organismos y poblaciones podrían jugar un papel relevante en, por ejemplo, la aparición de las clases de las aves, los reptiles y los mamíferos, e incluso en el surgimiento del phylum mismo de los seres vertebrados, en la historia de la evolución de las especies.

Los procesos naturales de selección son también estocásticos con los fenotipos de organismos y poblaciones preservados como sus efectos aleatorios. Si desplazamos a los organismos y poblaciones como los relata de la selección natural en favor de los procesos de selección estabilizadora, direccional y disruptiva; si además no separamos conceptualmente a los organismos y poblaciones de los medios ambientes cambiantes en los que están integrados como elementos constitutivos, entonces podemos ver que el carácter objetivo de esos procesos estocásticos es extrínseco a ellos, en virtud del ecosistema concreto en que están inmersos organismos y poblaciones. En otras palabras, los procesos de selección estabilizadora,

\footnotetext{
${ }^{8}$ Si las mutaciones involucradas tuvieran efectos de magnitud considerable en el fenotipo entonces, quizá, podrían encajar con lo que Mayr denomina evolución especiacional, un tipo de macroevolución, a escala geológica, caracterizada por estallidos de generación profusa, súbita y discontinua de nuevas especies, y que él considera compatible con la teoría del equilibrio puntuado de Eldredge y Gould (1972). (Véase, Gould (2002): 922), donde cita a Mayr de Speciational evolution and punctuated equilibria, en A. Somit y S. A. Peterson, eds., The Dynamics of Evolution, Ithaca New York: Cornell University Press, 1992: 48).
} 
direccional y disruptiva no operan fuera de cualquier medio ambiente, por lo que no podemos decir que intrínsecamente son deterministas o estocásticos (a diferencia de las mutaciones genéticas que podemos conceptualizarlas separadas del resto de los procesos genéticos y selectivos al ser producidas de manera espontánea por replicación). Sólo extrínsecamente, en función de un medio ambiente concreto, esos procesos producen una selección de fenotipos de organismos y poblaciones aleatoriamente, a causa de una variedad de factores externos a ellos que son contingentes y azarosos. De esta manera, los procesos de selección natural son objetivamente estocásticos de modo extrínseco, en virtud de un medio ambiente concreto.

Concluyo, pues, con la tesis de la ubicuidad del azar objetivo en tres tipos de procesos claves en la evolución de las especies.

\section{Bibliografía}

Avers, Charlotte J. (1989). Process and Pattern in Evolution, New York: Oxford University Press.

Ayala, Francisco J. (2012). Evolución: las grandes cuestiones (trad. Joandomenec), Barcelona: Ariel, 2012.

Brandon, James (2008). "Natural Selection", Stanford Encyclopedia of Philosophy. Ed. E. N. Zalta. http://plato.stanford.edu/entries/natural-selection.

Cushing, J. T. (1989). "A background essay”, Philosophical Consequences of Quantum Theory. Eds. J. T. Cushing \& E. McMullin, Notre Dame: University of Notre Dame Press: 1-24.

Darwin, Charles (1859). El origen de las especies (trad. Rafael Rutiaga), México: Grupo Editorial Tomo, 2005.

Eldredge, Niles (1998). The Pattern of Evolution, New York: Freeman.

Eldredge, Niles \& Stephen Jay Gould (1972). "Puntuacted equilibria: an alternative to phyletic gradualism", Models in Paleobiology. Ed. T. J. M. Schopf, San Francisco: Freeman Cooper: 82-115.

Ereshefsky, Marc (2010). "Species", Stanford Encyclopedia of Philosophy. Ed. E.N. Zalta. http://plato.stanford.edu/entries/species.

Feller, William (1950). Introducción a la teoría de las probabilidades y sus aplicaciones (trad. Salvador Morales Baca), vol. I, México: Limusa, 1988. 
Griffiths, Anthony J. F., William M. Gelbart, Jeffrey H. Miller \& Richard C. Lewontin (1999). Genética moderna, (trad. Francisco J. Murillo Araujo et al), Madrid: McGraw Hill Interamericana, 2000.

Giere, Ronald (1976). "A Laplacean Formal Semantics for single-case Propensities", Journal of Philosophical Logic 5: 321-353.

Gould, Stephen Jay (2002). La estructura de la teoría de la evolución, (trad. Ambrosio García Leal), Barcelona: Metatemas, 2004.

Kardong, Kenneth V. (2005). An Introduction to Biological Evolution, New York: McGraw-Hill.

Kunn, Thomas S. (1970). "¿Lógica del descubrimiento o psicología de la investigación?”, Crítica y desarrollo del conocimiento científico (trad. F. Hernán). Eds. I. Lakatos y A. Musgrave, Barcelona: Grijalbo, 1975.

Laplace, Pierre Simon de, (1814). Ensayo filosófico sobre las probabilidades, (trad. Pilar Castrillo), Madrid: Alianza Universidad, 1985.

Martínez, Sergio (1991). "El azar en la mecánica cuántica: de Bohr a Bell", Crítica, vol. XXIII, núm. 69: 137-154.

Mayr, ERnest (1991). Una larga controversia: Darwin y el darwinismo (trad. Santos Casado de Otaola), Crítica: Barcelona, 1992.

Rae, Alastair (1986). Física cuántica. ¿Ilusión o realidad? (trad. Miguel Ferrero Melgar), Madrid: Alianza Universidad, 1988.

Sober, Elliott (2000). Philosophy of Biology (2nd. edition), Colorado/Oxford: Westview Press.

Suppes, Patrick (1970). A Probabilistic Theory of Causality, Acta Philosophica Fennica, XXIV, Amsterdam: North-Holland.

(1984). Probabilistic Metaphysics, New York: Basil Blackwell.

Enviado: 19/10/2015

Aceptado: 7/04/2016

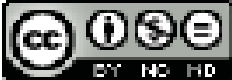

ENDOXA está bajo una licencia de Creative Commons Reconocimiento-NoComercial-SinObraDerivada 4.0 Internacional 